\title{
EL MERIDIANO Y EL ANTIMERIDIANO DE TORDESILLAS EN LA GEOGRAFÍA, LA NÁUTICA Y LA CARTOGRAFÍA
}

\author{
POR \\ RICARDO CEREZO MARTÍNEZ \\ Capitán de Navio
}

\section{ANTECEDENTES}

Hasta 1640 -e incluso después- las historias de Portugal y de España, entiéndase Castilla, están tan estrechamente relacionadas que para estudiar seriamente la de uno de esos dos países se ha de conocer, siquiera en términos generales, la del otro. El Tratado de Tordesillas y sus diversas implicaciones políticas, jurídicas y geográficas son una parcela importante de la historia común, que se engarza en los respectivos propósitos de proyección en Africa e islas atlánticas, viejo objetivo perseguido por los reyes de Portugal y de Castilla. Tales aspiraciones tenían que encontrar $-\mathrm{y}$ encontraron- contestación recíproca de una y otra parte.

Culminada la Reconquista en Portugal y afirmado el poder real, Juan I adoptó como eje de su política exterior la que se podría denominar "solución atlántica», iniciando la expansión paulatina de su influencia política en África con la conquista de Ceuta en 1415. La progresiva llegada de los navegantes lusos a cabo Bojador (1435), cabo Blanco (1441), y Arguim y Senegal (1444); la conquista de Tánger y Arcila y el asentamiento en San Jorge de Mina en el Golfo de Guinea (1471), enclave de gran importancia para almacenar mercancías, el oro, marfil y esclavos y reexpedirlas a la metrópoli lisboeta, fueron los hitos más señalados en el fortalecimiento de la premeditada proyección portuguesa en el continente negro.

En esta situación, si la conquista de Ceuta mediatizaba la expansión castellana en su «frontera» del norte África, el dominio portugués de la costa al sur de Bojador le ponía trabas en el 
Atlántico; a la vez que fortalecía afirmaba un monopolio mercantil próximo al ejercicio de una política del mare clausum en el océano afro-atlántico. Para los castellanos la libre navegación a las Canarias, a las costas sahariana y al Golfo de Guinea quedó en entredicho cuando la diplomacia de Alfonso $V$ aseguró el carácter legal de los logros expansivos lusitanos con las bulas de Nicolás V, Romanos Pontifex (1454), que confirmaba el derecho de posesión en las costas de África al sur de cabo Nun y Bojador, y la de Calixto III Inter Coetera (1456), que lo hacía extensivo hasta la India y daban opción al monopolio de la ruta marítima hasta este legendario país asiático.

La implicación marítima consecuente de la guerra entre Castilla y Portugal por la sucesión al trono vacante de Enrique IV y el apoyo de los Reyes Católicos a los marinos andaluces para comerciar en el golfo de Guinea dieron lugar a múltiples enfrentamientos armados en la mar hasta que se firmaron las paces de Alcáçovas-Toledo en 1479 y 1480. Con este acuerdo Alfonso V renunciaba a sus pretensiones a la corona castellana y a la posesión de las Canarias y Fernando e Isabel a las suyas sobre la costa africana y a la navegación y tráfico mercantil de sus súbditos al sur de las Canarias y, por supuesto, a las islas Azores, Madera y Cabo Verde, La pretensión de adjudicarse las Canarias fue propicia a los reyes de Castilla desde que Juan de Bethencourt, su conquistador (1402 y siguientes), vasallo de Enrique III, les ofreció las opciones de posesión de las islas a cambio de determinados privilegios.

Por los acuerdos de Alcáçovas-Toledo los marinos castellanos no podían surcar las aguas oceánicas al sur del paralelo de las Canarias, pero eran libres de hacerlo a poniente y al norte de ese paralelo, con lo que tenían expedita la libertad de navegar en los grandes espacios del Atlántico occidental. Los Reyes Católicos adquirían así, anticipadamente, inesperados derechos sobre las islas y tierras que años más tarde descubrieron Colón y quienes siguieron explorando el Nuevo Mundo. Y de conformidad con esos derechos, producido el primer hallazgo de tierras en ultramar, solicitaron un nuevo reparto de influencias en el Atlántico al papa Alejandro VI, que éste sancionó en 1493, mediante la promulgación de varios breves y bulas legitimando la propiedad de las recién halladas posesiones castellanas:

-3 de mayo, el breve secreto Inter Coetera concedía a los Reyes Católicos los derechos de las tierras descubiertas que no 
estuvieran bajo dominio de otro príncipe cristiano, con los mismos derechos que las anteriores bulas papales otorgaron a los monarcas portugueses.

-3 de mayo, bula Eximie Devotionis, resumen del anterior y confirmación de los privilegios portugués.

-4 de mayo, la bula Inter Coetera II, o bula de partición, limitaba la jurisdicción asignada en las bulas anteriores mediante un meridiano, de polo a polo, trazado 100 leguas al oeste de las islas Azores y de Cabo Verde según la cual las tierras situadas a poniente de esa línea, hasta la India, quedaban incluidas en la demarcación de Castilla y las del este a Portugal.

-25 de junio, la bula Piis Fidelium otorgaba el vicariato de Indias a fray Bernardo Boil.

-25 de septiembre, la bula Dudum Siquidem, modificaba la Inter Cetera II ampliando la jurisdicción de los Reyes Católicos hasta la India y las regiones orientales de la línea ecuatorial. Esta bula, dictada en el curso de las conversaciones entre los embajadores portugueses y los representantes españoles para determinar el trazado de un nuevo meridiano divisor de las respectivas demarcaciones oceánicas, modificaba la Inter Cetera II y permitía a los navegantes de los Reyes Católicos el acceso a la India y a descubrir en los mares ecuatoriales de Oriente; un privilegio lesivo para los fines de Juan II en estas regiones, contrapartida diplomática de Isabel y Fernando que aseguraba sus intereses en aquella región antes de alcanzar un acuerdo en Tordesillas respecto del trazado del nuevo meridiano de demarcación.

De todos estos documentos pontificios es de interés para nuestro tema la bula Inter Cetera II, que determinaba la posición del meridiano de partición propuesta por Colón, de acuerdo con una carta que la reina Isabel le escribió veinte días antes de que zarpara de Cádiz para su segundo viaje, En ella hacía referencia a la raya que vos dijisteis que debia venir en la bula del papa (1): esta raya era una línea agónica de la declinación magnética que cruzaron las naves descubridoras en la noche del 13 de septiembre de 1492, cuando la flor de lis de la aguja de marear se desvió al noroeste en vez seguir apuntando al nordeste como era normal en el Mediterráneo y aguas del Atlántico afro-europeo desde tiempo inmemorial.

(1) El 5 de septiembre de 1493, carta Transcrita por Martín FERNÁNDEZ DE Navarrete, Colección de los viajes y descubrimientos, tomo II, doc. LXXI. 


\section{ASESORAMIENTO DE LOS REYES DE ESPAÑA ANTES DE ADOPTAR UNA DECISIÓN SOBRE EL TRAZADO DEL MERIDIANO DE TORDESILLAS}

Como era de esperar Juan II de Portugal, que se consideraba perjudicado en sus competencias atlánticas con la promulgación de la bula Inter Coetera II, pidió de inmediato a los Reyes de España modificar la posición del meridiano trasladándolo más al oeste de las 100 leguas establecidas. Por su parte los monarcas españoles, apremiados por las negociaciones iniciadas con la llegada de los delegados portugueses a la corte el 15 de agosto de 1493, dictaron cartas a diversas personas de su confianza, entendidas en cosmografía, que desvelan algunas vicisitudes interesantes del preludio del Tratado de Tordesillas.

El 18 de agosto instaron a Colón a que preparase con prontitud su flota en Cádiz y abreviara su partida -en el segundo viaje - para asegurar la posesión de las tierras descubiertas, recordándole que antes de darse a la vela les enviara la carta de marear en la que figuraban sus descubrimientos (2). Los monarcas habían leído el Diario de navegación que Colón les entregó al regreso de su primer viaje y como éste aún no les había proporcionado dicha carta resolvieron asesorarse debidamente para conducir las negociaciones sobre la demanda de Juan II. Con este propósito el 26 de agosto del mismo año 1493 el arzobispo de Toledo, Pedro González de Mendoza, personaje de entera confianza de los reyes, pidió al lapidario y cosmógrafo Jaime Ferrer de Blanes que se trasladara a Barcelona -donde a la sazón residía la corte-con el Mapamundi y otros instrumentos si teneis tocantes á Cosmografía (3).

Este mapamundi es hoy desconocido. Sin embargo el que González de Mendoza tomara parte en el estudio del proyecto del primer viaje de Colón, e influyera particularmente en la decisión final de los reyes en Santa Fe, son circunstancias que otorgan suma importancia a ese documento, máxime si se tiene en cuenta que en su carta a Ferrer el arzobispo lo singulariza con el artículo el. No se trata por lo tanto de un mapamundi cualquiera, sino uno muy concreto, conocido por ambos, cuyo contenido geográfico y náutico se quiere someter a estudio, puesto que también le dice que lleve consigo a Barcelona otros instrumentos útiles en cosmografía. Como ese mapamundi no es

(2) Ídem, doc. LXVII.

(3) Ídem, Ibídem. 
el que los reyes han pedido a Colón y es conocido por Mendoza y Ferrer, resulta lícito aceptar la hipótesis de que era también conocido por Fernando e Isabel y que se trata de una copia de las que se utilizaron para estudiar el proyecto del primer viaje colombino; asimismo se infiere que Ferrer pudo ser uno de los cosmógrafos que participaron en los estudios realizados por expertos para valorar la factibilidad de ese viaje. Es de suponer que Ferrer cumplió el mandato de Mendoza y que sobre ese mapamundi se fundamentaron las primeras ideas relativas a la posición del meridiano de Tordesillas.

El 5 de septiembre la Reina Isabel pidió de nuevo a Colón, con urgencia, la carta de marear que de él esperaba, toda vez que las conversaciones con los representantes de Juan II estaban en curso y quería disponer de información geográfica más fidedigna para perfilar un acuerdo. El mismo día 5, el Rey y la Reina remitieron a Colón otra misiva, pidiéndole consejo sobre la posición de la nueva línea divisoria pues

algunos quieren decir (...) que entre la ruta seguida por las naves para llegar al cabo de Buena Esperanza o al golfo de Guinea podrá haber Isla y aun Tierra Firme (...) y porque sabemos que desto sabeis vos más que otro alguno, vos rogamos que luego nos envieis vuestro parecer en ello, porque si conviniera, y os pareciere que aquello es tal negocio cuan acá piensan, se enmiende la Bula; por eso por servicio nuestro que luego nos lo escribais (4).

La existencia de esas tierras era de posición incierta pero conocida antes de que Colón llegara en su primer viaje a las islas Lucayas. No sólo eran algunos, sino muchos los que sabían que la región sudoriental de Asia se remataba en una gran península -la actual Indochina- identificada con el Áurea Quersoneso y que junto a su costas existía multitud de islas. El primigenio mapamundi de Abrahan Cresques (1375) y los posteriores mapas de Fra Mauro (1459), Henricus Martellus (1490) y Martín Behaim (1492), por citar los más conocidos, representaban islas, perfiles de la costa oriental de Asia que afirmaban la opinión de que aparte de las islas descubiertas por Colón quedaban aun muchísimas más por descubrir al sur y en torno a la línea equinoccial. En este sentido y a petición de la Reina Isabel, el 5 de agosto de 1495 Jaime Ferrer escribió su parecer al Almirante del Mar

(4) Ídem, doc, LXXI. 
Océano respecto de los lugares donde se encontraban las riquezas naturales. Decía Ferrer que (a) la vuelta del equinoccio son las cosas grandes y de precio, como son piedras finas y oro y especias $y$ drogaría (5). Se conocía, pues, la existencia de tierras en aquella región de los confines de Asia y los Reyes de España eran conscientes de la suma importancia política que significaba el trasladar el meridiano más al oeste.

\section{LA CARTA DE MAREAR DEL SEGUNDO VIAJE DE COLÓN, NECESARIA PARA SITUAR EL MERIDIANO DE TORDESILLAS}

No sabemos si Colón dio o no su parecer a los Reyes antes de darse a la vela en Cádiz con su flota para colonizar la isla Española, aunque bien pudo hacerlo, porque dispuso de tiempo suficiente para ello (6). Si contestó a la cuestión que formularon los monarcas puede darse por seguro que no aconsejó el trazado de la línea divisoria en la longitud geográfica acordada en Tordesillas. Un traslado del meridiano a poniente limitaba su jurisdicción de Almirante del Mar Océano, y como hombre muy aferrado a sus convicciones cosmográficas para él el meridiano de las Azores, el de la bula papal, era más que una mera línea imaginaria trazada de polo a polo como los demás meridianos. El fenómeno del cambio de variación de las agujas de marear observado en su primer viaje, comprobado durante su regreso y también en la ida de su segunda expedición, le indicaba indeleblemente la transición de un hemisferio de la Tierra a otro distinto.

Aquella línea era equiparable a la línea equinoccial, y cuando la cruzaba observaba otros efectos distintos al del cambio de variación en las agujas de marear. Pasados varios años, en el relato de su tercer viaje escribía a los Reyes: Cuando yo navegué d'España a las Indias, falló luego, en passando ciento leguas a Poniente de las Açores, grandissimo mudamiento en el cielo e en las estrellas y en la temperançia del aire y de las aguas del mar, y en esto e tenido mucha diligencia en la experiencia (...) y esto es en allegando alli a aquella línea, como quien traspone una cuesta.

Fernando e Isabel recibieron a tiempo la carta de marear elaborada por Colón en el segundo viaje, la única que contenía todas las islas últimamente descubiertas, remitida en enero de

(5) Ídem, doc LXVII.

(6) Las dos últimas misivas de los Reyes a Colón se fecharon el 5 de septiembre y él se dio a la vela en Cádiz el 25 de ese mismo mes. 
1494, desde la recién fundada ciudad de Isabela, junto con el relato del viaje y un Memorial de los que fue portador Antonio Torres que llegó a la corte antes del 13 de abril de 1494 (7). Es decir dos meses largos antes de que el 7 de junio de 1494 se firmara el Tratado de Tordesillas, con tiempo suficiente para poder estudiar con detenimiento la posición geográfica del nuevo meridiano de partición de competencias a la vista de una representación de las tierras recientemente descubiertas.

Esa carta de marear es desconocida, pero la explicación que de ella dio el Almirante en su relación del viaje contiene suficientes datos descriptivos para entender que se trataba de una carta plana cuadrada e inferir cuál era su contenido geográfico general. Lógicamente en ella figuraban las Antillas que descubrió en el segundo viaje y Colón trazó en ella además meridianos y paralelos separados un grado - de $562 / 3$ millas por grado- de modo que se podía medir el

camino ques de España al comienço o fin de las Yndias y verán en quál distançia las unas tierras de las otras rresponden; beran en la dicha carta una rraia que pasa de setentrion en austro, ques vermeja, y pasa por çima de la ysla Ysavela sobre el Fin d'España, allende del qual estan las tierras descubiertas el otro viaje, y las otras de agora de aca de la rraia, se entiende (8).

La composición de la carta se hizo por tanto en base a una escala adecuada para apreciar el espacio oceánico con detalle suficiente de la posición y distancias itinerarias y graduales entre Europa, las islas Canarias y las descubiertas en el primero y el segundo viajes.

En el relato del viaje Colón hacía referencia al comienço o fin de la Yndias y al Fin d'España y lo indicaba en la carta de marear con un meridiano trazado en color bermejo, que delimitaba las tierras descubiertas en los dos viajes y pasaba, en consecuencia, por el extremo oriental de La Española, que él denominó Ysavela. Dado que no aludía a la nueva línea de demarcación, cuyo resultado del acuerdo firmado en Tordesillas desconocía

(7) Los Reyes acusaron recibo de los documentos llevados por Torres en carta dictada en esa fecha en Medina del Campo, Transcrita por FERNÁNDEZ DE NAVARRETE, [1], doc LXXIII.

(8) Manuscrito del Libro Copiador de Cristóbal Colón Transcripción de Antonio Rumeu de Armas. Madrid, Ed. Testimonio, 1989, tomo II, págs. 451-452. En La Cartografía náutica española en los siglos XV, XVI y XVII Madrid, CSIC, 1994, explicamos los detalles de construcción de esta carta, de singular interés para la historia de la cartografía. 
por encontrarse en La Española, es menester aclarar la intención del significado que dio a estos términos, que esperaba fueran entendidos por los Reyes.

Colón aludía también al golfo de España (9) cuando anunciaba que había enviado una carabela a reconocer la isla Española al mando de un tal Marque - quizá Márquez- en dirección a ese golfo, pues suponía que en aquella parte de la isla Española había un gran rrio y que traya oro (10) y quería comprobar si esto era o no cierto; como la carabela tenía que rodear la isla "fasta enfrente de Montechristo de la otra parte del austro" (11) tardó bastante tiempo en regresar a Isabela por causa de los vientos contrarios.

Colón repitió el término golfo de Spaña (12), alterado en la ortografía al referirse a su incursión a la región de Cibao. Entendía por "golfo de España" el espacio de océano extendido entre España y las Indias que él descubrió en sus dos primeros viajes. Los términos golfo, cruzar el golfo, etcétera, adjetivados con el apelativo España denotaban que en su mente bullían ideas ligadas a hechos muy recientes y de trascendencia política relacionados con la petición del rey de Portugal para trazar un nuevo meridiano de demarcación situado más oeste que el de la bula Inter Coetera, que él mismo propuso y le concernía a él por su condición de Almirante del Mar Océano. El significado que atribuía al "Fin d'España» había de entenderse como límite del golfo que comprendía el espacio marítimo de interés para la Corona y para él mismo. La palabra España adjetivaba intencionadamente los vocablos Fin y golfo por cuanto relacionaba ideas espaciales y de pertenencia que él mismo explicó al citar los momentos en los que en su viaje anterior decidió regresar a España:

al fin del año pasado quando della [isla Española] yo partí para Castilla, adonde yo hallé [el] Fin d'España mas hallé acá al oriente una gran provinçia, que de tierra mui baja y llana, y que deste cavo a Fin d'España corre al sueste; la cual no ví, al tiempo de mi partida porque yo llevé el camino del este, al cuarta del nordeste, y partí de noche, de manera que la tierra me quedava a la mano derecha, por ser baja y al rodeo del sueste, no veo della vista; asi que agora la rreconoçi toda, del comienço hasta el cavo de (blanco). Ay buen tiempo, adonde los

(9) Libro Copiador, idem, tomo II, pág. 457.

(10) Ibídem, pág. 457.

(11) Ídem, pág. 464.

(12) Ídem, documento III, pág. 472. 
yndios llaman Samaná, adonde agora no quise anclear por la priesa (13).

El cabo en cuestión es el que bautizó de Sant Theramo el 16 de enero de 1492 situado en el extremo oriental de la isla Española.

Es decir, en el relato del segundo viaje Colón amplió lo que escribió él al año anterior en primero después de abandonar el Golfo de las Flechas, o Samaná, cuando navegaba al rumbo E 1/4 NE después de andar 64 millas -51 millas náuticas-, hallándose a unas 15 millas náuticas al NE del actual cabo Rafael, y puso la proa al SE para ir en busca de la isla de Carib. Pero cambió de idea al ver el disgusto de la gente y ante la bondad del viento para volver a España y decidió arrumbar al N 1/4 E. La última tierra que entonces vio de la Española fue la del cabo de Sant Theramo o San Telmo, pero mientras navegaba al SE se apercibió de que existía otro cabo saliente de tierra baja: el que reconoció en el segundo viaje cuando dejó atrás la isla de San Juan. En este cabo, del que pudo comprobar que se extendía al sudeste, situó el Fin d'España, no podía ser otro que el actual cabo Engaño (14), situado en el extremo más oriental de la isla Española.

Es evidente, pues, que el meridiano de color bermejo indicaba la separación de dos regiones geográficas, la que comprendía las tierras descubiertas en el primer viaje - la península de Cuba y la isla Española o Cipango, principalmente- y las islas reconocidas en el segundo, todas dentro de la demarcación española, por eso insistía en llamar la atención de que la porción de océano comprendido al oeste de la rraya vermeja era el golfo de España.

A la vista de la carta de marear de Colón los Reyes Católicos y sus asesores debieron tener un panorama geográfico de los descubrimientos bastante claro para adoptar una decisión fundamentada.

\section{EL CRITERIO ADOPTADO PARA SITUAR EL MERIDIANO DE TORDESILLAS; VICISITUDES}

El Tratado de Tordesillas determinó el trazado de un meridiano de polo a polo, 370 leguas al oeste de las isla de Cabo Verde,

(13) Libro Copiador [8] tomo II, pág. 454.

(14) Diario de primer viaje. Se trata del Cabo de San Telmo, Hernando Colón Historia del Almirante, cap. XXXVII. LAS CASAS se equivoca al identificarlo con el cabo Engaño, Historia de las Indias, lib. I, cap, LXVIII. 
de modo que las tierras de allende ese meridiano pertenecían a los Reyes de España y las situadas al este del mismo al rey de Portugal. Se incluyó una cláusula transitoria en virtud de la cual y, en previsión de que en los trece días siguientes a la fecha de la firma del mismo -7 de junio de 1494- las naves españolas hallaran nuevas tierras, el meridiano vigente hasta entonces sería el trazado a 250 leguas de las islas de Cabo Verde. Es decir, hasta el 20 de junio no entraría en vigor la validez del meridiano trazado a 370 leguas de dichas islas (15). A nuestro modo de ver la razón de esta demora de trece días reside en el propósito de los Reyes Católicos de ganar tiempo para que Bartolomé Colón -que zarpó de Sevilla al mando de tres naves en el mes de abril de 1494- pusiera en antecedentes a su hermano Cristóbal para que se esforzara en descubrir nuevas tierras en cumplimiento de las instrucciones recibidas para su segundo viaje, que también incluían la misión de confirmar si Cuba era o no tierra firme. Antes de que Bartolomé llegara a Isabela el Almirante ya había partido para investigar la costa meridional de Cuba y luego dispuso realizar exploraciones en los entornos de las islas Lucayas, según decía en la carta de enero de 1494 remitida con Antonio Torres, junto con el Memorial y la carta de marear ya citados.

En base a la bula papal de 1493 y a las conveniencias de cada una de las partes, durante los meses de marzo-junio de 1494 los delegados portugueses negociaron con los castellanos en Tordesillas la determinación de los hemisferios de la Tierra sobre los que tenían competencias descubridoras sus respectivos monarcas. La resolución hubo de fundamentarse en datos concretos, de ningún modo en supuestos arbitarios, ni conocimientos ciertos de la existencia de tierras brasileñas de parte portuguesa, como alegan algunos historiadores, ya que de ser así en las conversaciones de Tordesillas este hecho habría sido argumento definitivo para que los embajadores de Juan II hubieran reivindicado sus derechos sobre ese territorio en virtud de la vieja resolución papal que concedía la posesión de territorios descubiertos no pertenecientes a reyes cristianos.

Creemos, por lo tanto, que el acuerdo de Tordesillas se adoptó a la vista de una carta de marear, que no podía ser otra que la remitida por Colón, única entonces en la que figuraban las islas descubiertas en sus dos viajes. Fue precisamente la posición de las islas halladas en el segundo la que sirvió de referencia para

(15) Tratado de Tordesillas, Madrid, Servicio de Publicaciones del Ministerio de Educación y Ciencia, 1973. 
trazar el meridiano de Tordesillas, mediante una decisión salomónica, en la mitad de las 700 leguas que separan las islas de Gran Canaria y Dominica, como puede comprobarse en la primera carta mapamundi conocida en la que se representa el meridiano con un error de un $2 \%$, es decir la carta anónima denominada de Cantino de c. 1502. En el Tratado no se hizo constar más referencia de origen que las islas Cabo Verde, omitiéndose las Azores tenidas en cuenta en la bula Inter Coetera II.

Ante el hecho, real, de que las islas Azores y las de Cabo Verde tomadas como origen en esta bula no están en un mismo meridiano, autores modernos han representado gráficamente sobre los mapas, con precisión superflua, la línea divisoria papal y del meridiano de Tordesillas materializadas por dos meridianos que determinan una línea quebrada, cuyo tramo septentrional está desfasado hacia el oeste respecto del meridional en una cuantía igual a la diferencia de longitud entre los dos grupos de islas. Es este un propósito de innecesaria exactitud, falto de sentido en 1494, puesto que en los años anteriores ambos grupos de islas se consideraban en una misma longitud geográfica, ello aparte de que la división decretada en la bula de Alejandro VI, aun refiriéndola a los dos archipiélagos como origen, la señalaba «una línea del Polo ártico que es el Setentrión al Polo antártico que es el mediodía». No se justifica por lo tanto la idea de representar esa línea, que es un meridiano, por una línea quebrada (16).

La creencia de que las islas Azores y las de Cabo Verde estaban en un mismo meridiano no era un caso único en la apreciación de las longitudes, dada la dificultad que entrañaba su cálculo por medio del cálculo de la hora de una eclipse, - conjunción, y oposición de luna y planetas, - comparándola con la hora de la misma efemérides astronómica tabulada para un lugar de longitud conocida. Se tiene otro ejemplo en la longitud de la mayor de las islas Berlengas - frente a cabo Carvoeiro- considerada en el mismo meridiano que el cabo de San Vicente, siendo así que hay más de medio grado - 30 millas- de diferencia en la longitud de ambos lugares. No excesiva si se quiere aminorar el error aduciendo las deficiencias técnicas y de procedimientos náuticos de la época, pero importante por cuanto la distancia entre aquella isla y el cabo de San Vicente apreciada

(16) En cartas mapamundi posteriores como las de Juan de la Cosa (1500) y de Cantino (1502) los archipiélagos de Azores y Cabo Verde aparecen ya situado en longitudes distintas. 
sobre ese supuesto meridiano era base de medida para las distancias náuticas, adoptada para calcular el módulo de conversión de millas en grados y viceversa (17).

Recordemos, por otra parte, que las cartas de marear a finales del siglo XV eran muy generales y en su reducido tamaño se representaban grandes extensiones marítimas en las que era difícil discriminar las distancias de separación entre las islas de un mismo archipiélago, como el de Cabo Verde, razón por la que en el Tratado de Tordesillas se adoptó como origen éste grupo de islas en todo su conjunto, sin precisar la isla que debería servir de punto de partida para medir la distancia del lugar situado a 370 leguas, sobre el que se debería trazar el meridiano divisorio aceptado por ambas partes. No se consideró la figura de este meridiano, sino el método para determinar la medición de las leguas desde las islas del grupo de Cabo Verde. La falta de acuerdo respecto de la isla que debería elegirse como origen surgió más tarde cuando la posición exacta del meridiano las 370 leguas sumaba o restaba a la corona portuguesa una considerable extensión del Brasil pues la diferencia de longitud entre la más oriental y la más occidental de las islas del archipiélago, San Antón y Boa Vista -o también la isla de la Sal- implicaba un trazado de la línea de demarcación más al oeste o más al este, favorable para el rey de Portugal si se adoptaba la primera o para el monarca español si la segunda.

El Tratado de Tordesillas fue confirmado en Arévalo el 2 de julio de 1494 por los Reyes Católicos y en Setúbal el 5 de septiembre por Juan II. Ni aquéllos ni éste se ocuparon de solicitar la ratificación papal, ni lo hizo el rey Manuel cuando sucedió a su padre en octubre del año siguiente. Manuel I de Portugal, constante en el curso de su reinado en la consecución de seguridades y privilegios sobre las tierras descubiertas por los náutas de su país, no se ocupó de ese requisito hasta once años después de haberse firmado el Tratado, el 24 de enero de 1506. Lo solicitó súbitamente del papa Julio II porque desde el punto de vista de su política atlántica en ese año se habían acumulado importantes incidencias que podían afectar a sus competencias territoriales, a pesar de que el 1 de junio de 1497 había conseguido del mismo Julio II la bula Ineffabilis que le concedía la

(17) Martín CORTÉs en su Breve compendio de la sphera y de la arte de navegar, de 1551. Capítulo II, folios LXV y LXV vuelto, explica cómo los navegantes españoles utilizaban esta base para calcular dicho módulo. 


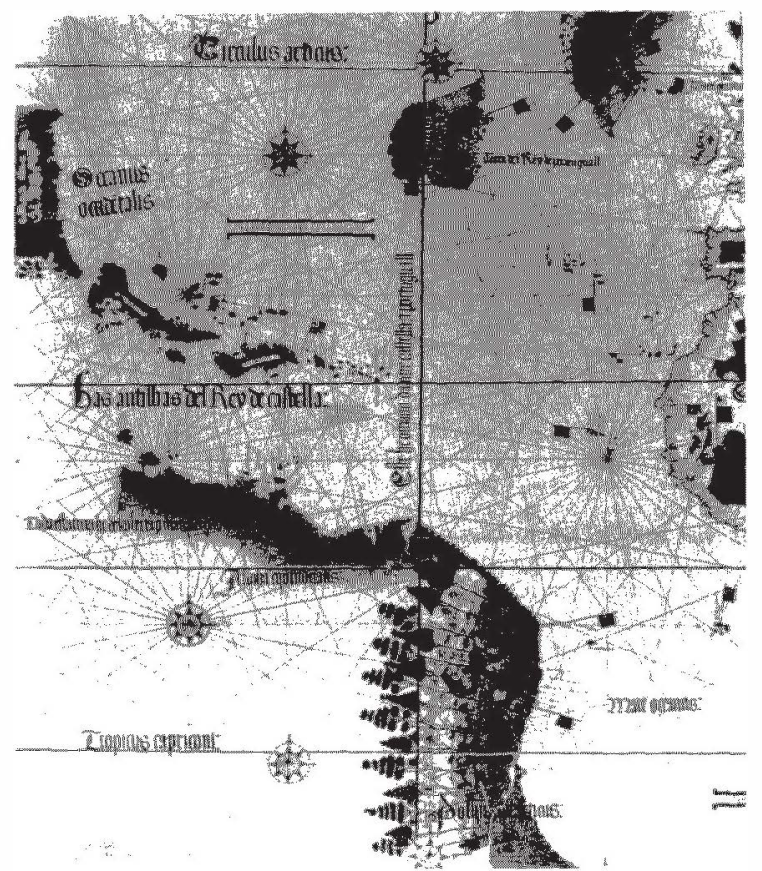

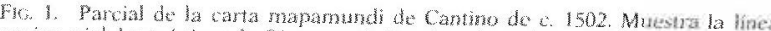

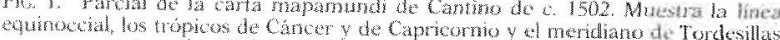

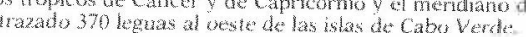


investidura de los reinos que conquistara sin que ningún rey cristiano pudiera oponerse a su soberanía.

Los navegantes españoles habían reconocido ya gran parte del litoral de la tierra firme sudamericana y en 1502 Cristóbal Colón intentó acceder a la India buscando un estrecho en una región que resultó ser un istmo al parecer bañado en su costa occidental por el Índico. En 1505 Fernando el Católico había reunido en Toro una junta de navegantes, en la que se tomaron las decisiones de establecer asentamientos humanos en tierra firme y seguir buscando el acceso marítimo a la región de Asia, cuya riqueza explotaban en monopolio los navegantes lusitanos. $\mathrm{Y}$, sobre todo, fallecida la Reina Isabel y relegado de la gobernación de la corona castellana el Rey Fernando, suegros de Manuel I, el advenimiento de Felipe I de Habsburgo al trono de Castilla, como esposo de la Reina Juana, vaticinaba un cambio en las relaciones con Portugal y era conveniente recabar la sanción papal para legitimar sus competencias territoriales en ultramar en previsión de las actitudes que en política internacional adoptaba el nuevo Rey que asumía el gobierno de Castilla.

Tampoco podía ignorar el rey Manuel el litigio sobre el dominio de las Indias suscitado entre los Colón y el Rey Católico, que restaba al Almirante atribuciones de gobierno y administrativas, a la vez que le restituía algunas competencias y privilegios económicos, cuestión que podía tomar derroteros imprevisibles con el nuevo monarca, con quien no le unía ningún parentesco ni amistad, más bien al contrario dado el buen entendimiento entre Felipe y el francés Luis XII. Por otra parte la emisión de la bula de 1506 confirmatoria del Tratado de Tordesillas fue también una importante contrapartida anticipada al viaje a Roma de Bartolomé Colón a finales del mismo año, en busca del apoyo papal en las pretensiones familiares de posesión de las tierras descubiertas por el Almirante del Mar Océano.

Años más tarde, el 3 de noviembre de 1514, después de que Vasco Núñez de Balboa descubriera el Mar del Sur y los navegantes españoles comenzaron a explorar las costas del nuevo mar, Manuel de Portugal, consiguió que León X promulgara la bula Praecelsae devotionis adjudicándole los mismos privilegios que la Dudum siquidem (de 26 de septiembre de 1493) reconocía a los Reyes de Castilla, confirmando así el dominio de Portugal sobre la ruta de la India que le equiparaba con las concesiones que antaño habían logrado los Reyes Católicos. El meridiano de Tordesillas adquiría por lo tanto un valor jurisdiccional paritario 
de competencias exploradoras, de conquista y dominio sobre países regidos por príncipes no cristianos.

\section{LA POSICIÓN DEL MERIDIANO DE TORDESILlAS CALCULADA POR JAIME FERRER DE BLANES EN 1495}

En los acuerdos de Tordesillas se fijó un plazo de diez meses para que pilotos, cosmógrafos y marineros de España y de Portugal se reunieran en Gran Canaria con dos o tres carabelas y determinaran conjuntamente la posición del meridiano de partición. De adoptarse un procedimiento náutico para situarlo el problema era de difícil solución, toda vez que la posición en la mar habría de calcularse por el método de escuadría: es decir mediante la latitud y la distancia navegada a un rumbo dado. La latitud, deducida de la observación astronómica, podía hallarse con exactitud aceptable para ambas partes, pero en la determinación de la distancia, subsistía el defecto inevitable de su apreciación estimada a ojo, causa de errores apreciables.

El problema era menos complicado si el meridiano se trazaba sobre una carta de marear. Pero en este caso -igual que en el anterior - restaba la cuestión de elegir el módulo de conversión de millas en grados, discutible toda vez que estaban en uso los de $562 / 3,662 / 3$ o 70 millas romanas por grado, según la costumbre o formación de cada navegante; y los cosmógrafos de tradicional formación ptolemaica utilizaban la equivalencia de 500 estadios, o lo que es lo mismo 62,5 millas por grado, es decir 15 2/3 leguas (18). La aceptación de uno u otro módulo implicaba perjuicio para una de las partes litigantes y beneficio para la otra, habida cuenta que traía consigo un notable desplazamiento de la posición del meridiano hacia el este o al oeste. Este motivo de discrepancia se manifestó en toda su realidad en 1524 en las conversaciones de Badajoz-Elvas, cuando se discutieron los derechos de posesión de las Molucas.

Como Juan II de Portugal ratificó el Tratado el 5 de septiembre de 1494 los diez meses de plazo fijados para efectuar el cálculo posicional del meridiano de Tordesillas se cumplían el 5 de julio de 1495. No hay noticia de que los comisionados se reunieran en Gran Canaria para cumplir lo acordado en las deliberaciones. En España la solución del problema de determinar

(18) Una milla romana $=8$ estadios olímpicos. 
la longitud geográfica del lugar por donde deberia trazarse se confió al cosmógrafo Jaime Ferrer de Blanes, quien utilizó para una carta o un mapa, que denominó forma mundi en figura extensa, en el que plasmó gráficamente el meridiano de demarcación, según consta en un corto informe dirigido a los Reyes Católicos el 27 de enero de 1495. El mapa comprendía los hemisferios Ártico y Antártico, y porque más claramente sea visto la distancia de las dichas trescientas setenta leguas cuanto se extiende por linea occidental, partiendo del dicho Cabo Verde, por eso he yo intercecado [cruzado] de Polo á Polo la dicha distancia con lineas coloradas, que en el equinoccio distan veinte y tres grados (19). Este mapa es hoy desconocido, pero ello no resta a Ferrer la primacía de que se anticipara siete años al autor de la carta mapamundi de Cantino en representar en un mapa la posición del meridiano de Tordesillas.

En el informe de Ferrer decía que este meridiano, medida su posición sobre la línea equinoccial, estaba situado en los $23^{\circ}$ de longitud al oeste del meridiano de las islas de Cabo Verde, situadas en los $15^{\circ}$ de latitud. No explicaba cómo determinó los $23^{\circ}$, pero se comprueba que su cálculo es correcto utilizando la equivalencia de $662 / 3$ millas por grado en un sencillo cálculo trigonométrico (20). Los $23^{\circ}$ calculados por Ferrer se convierten en $20^{\circ}, 4$ sexagesimales (21) dado que la isla de Santiago de Cabo Verde, precisamente situada en los $15^{\circ}$ de latitud que considera Ferrer. Como esa isla esta situada $24^{\circ}$ al oeste de Greenwich, la línea de demarcación queda en los $20^{\circ}, 4+24^{\circ}=44^{\circ}, 4$ de longitud occidental.

El 28 de febrero del mismo año los Reyes solicitaron la presencia de Ferrer en Madrid donde dejó escrito un prolijo vot o parer, un informe, explicando el método náutico que podía utilizarse para calcular la posición de la línea de Tordesillas, a partir de las islas de Cabo Verde en su misma latitud (22). En este segundo informe citó con profusión las equivalencias entre el grado y la milla usados por Ptolomeo, Colón y toda una serie de autores de la antigüedad, sin valerse en sus cálculos de ninguna de ellas. Para situar el meridiano al oeste de Cabo Verde supuso que partiendo de las dichas islas [las 370 leguas] comprenden por

(19) FERnÁNDez de NaVARRETE, [1], tomo II, documento LXVIII.

(20) A saber: $370 \times \sec 15^{\circ}=383$ leguas medidas en la línea equinoccial; $383 \times 4=1.532$ millas romanas; $1.532: 662 / 3=23^{\circ}$.

(21) $23^{\circ} \times 662 / 3 \times 0,8: 60^{\circ}=20^{\circ}, 4$ sexagesimales.

(22) FERnÁNDEZ de NavarReTe, [1], doc, LXVIII. 


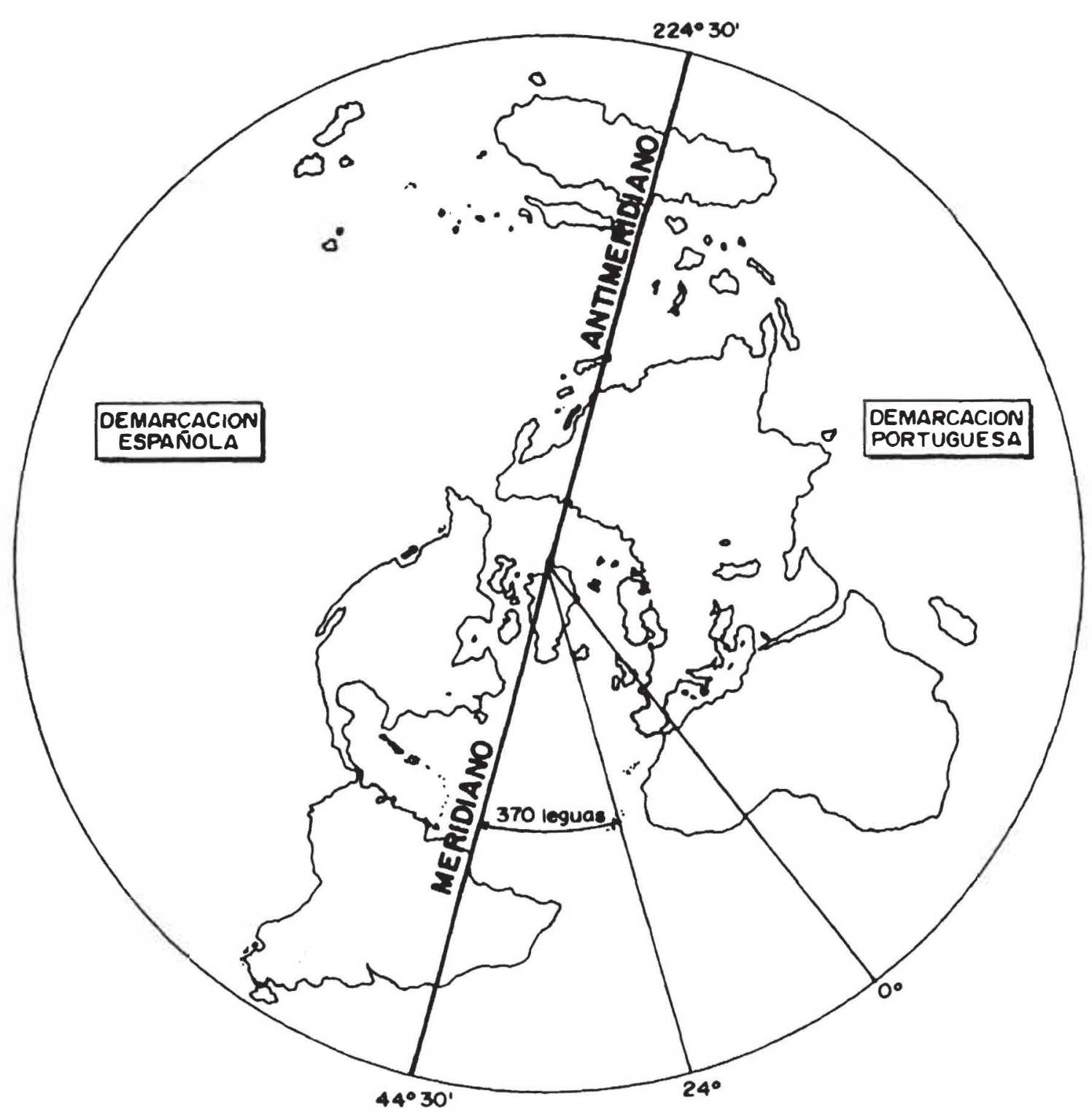

FIG. 2. El meridiano y antimeridiano de Tordesillas según Jaime Ferrer de Blanes trazado con datos náuticos actuales.

R. l., 1994, n² 202 
occidente diez y ocho grados, y cada grado en este paralelo comprende veinte leguas y cinco partes de ocho (23). Esta formulación era consecuencia del sistema de representación del mapa forma mundi, de proyección trapezoidal, que le obligó a adoptar ese número de 18 grados y su equivalencia de 20 5/8 leguas cada grado para conservar la distancia de las 370 leguas en la latitud de Cabo Verde, pues es sabido que las 370 leguas medidas en el paralelo de esas islas comprenden mayor número de grados que en la línea equinoccial (24).

Para situar el meridiano a 370 leguas al oeste de las islas de Cabo Verde mediante un procedimiento náutico Ferrer echó mano del cálculo trigonométrico, conforme con los procedimientos de la época. Si de dichas islas, estas islas en los $15^{\circ}$ de latitud, partía una nave siguiendo el rumbo W 1/4 NW y cuando alcanzaba la latitud de $18^{\circ} 1 / 3$ arrumbaba al sur hasta llegar a los $15^{\circ}$ de la latitud de partida - es decir el mismo paralelo de las islas de referencia - el meridiano seguido navegando a rumbo sur estaba situado a 370 leguas del lugar del que partió la nave y, por lo tanto, era el fijado en Tordesillas. Mediante este artificio Ferrer calculó la medida del cateto de un triángulo rectángulo plano conociendo un ángulo, el determinado por el rumbo de partida - de una cuarta, equivalente a $11^{\circ}, 25-$ y el cateto contiguo a este ángulo, es decir las 370 leguas fijadas en Tordesillas. Halló asi para el cateto opuesto una distancia de 74 leguas medidas sobre el meridiano buscado con la solución práctica del problema; estas leguas cifraban precisamente la diferencia entre las latitudes de $18^{\circ} 1 / 3$ y $15^{\circ}$. Los datos utilizados eran la latitud de partida, $15^{\circ}$; la latitud alcanzada, $18^{\circ} 1 / 3$, y el rumbo seguido

(23) Ibídem.

(24) Obsérvese que $18^{\circ} \times 205 / 8=370$ leguas. A la vista del pequeño y esquemático dibujo que figura al margen de un folio del informe de Ferrer, que transcribe Fernández de Navarrete y considerando que la base de unión de los dos triángulos que representan la citada forma mundi así como los lados que parten de los polos corresponden a círculos máximos, se deduce que el ángulo $\alpha$ que forman éstos con la base es de $82^{\circ}\left(\cos \alpha=23^{\circ}: 2: 90^{\circ}\right)$. Si en el triángulo que representa el hemisferio norte se traza una recta paralela a la base a una distancia que equivalente a $15^{\circ}$ de latitud, el segmento $X$ de esa recta comprendido entre los lados equivale en dimensión a la distancia de 370 leguas. Si ahora se proyecta ese segmento $\mathrm{X}$ sobre la base y se denomina $\mathrm{Y}$ a cada uno de los dos segmentos laterales que determina esa proyección, se puede escribir que $23^{\circ}=$ $2 \mathrm{Y}=2 \mathrm{Y}+\mathrm{X}$, y tag. $\alpha=15^{\circ}: \mathrm{Y}$. Resolviendo este sistema de ecuaciones resulta que $\alpha=82^{\circ}$ y X $=19^{\circ}$, valor muy próximo a los $18^{\circ}$ que Ferrer asigna al tramo occidental del paralelo de Cabo Verde, límite de las 370 leguas. Si se hace $\alpha=$ $80^{\circ}$, valor que seguramente utilizó Ferrer para dibujar su forma mundi, resulta $\mathrm{X}$ $=18^{\circ}$. Para obtener la distancia de 370 leguas Ferrer adoptó la equivalencia de $205 / 8$ leguas por grado y las multiplicó por los $18^{\circ}$ que hemos deducido. 
por la nave, es decir los que menor cuantía de errores podían introducir en los cálculos para la resolución del problema.

Dado que el triángulo rectángulo plano considerado por Ferrer se situaba en una zona de latitudes bajas, donde la superficie de la Tierra puede considerarse plana, los errores de cálculo por no haber resuelto un triángulo esférico eran mínimos. No se podía objetar, pues, que su solución fuera inadecuada en 1495: era sencilla y aceptable en relación con los medios y técnicas de navegación de entonces. Prescindió de la distancia navegada, causa principal de los errores en la determinación de la posición en la mar, y fió su cálculo a la facilidad de mantener un rumbo constante en la mar y en la determinación de la latitud del punto de llegada mediante la fácil medición de la altura de la estrella Polar. La solución era matemáticamente aceptable aún teniendo en cuenta los errores propios del mantenimiento del rumbo exacto y de los efectos del abatimiento de la nave y de las corrientes, que podían ser deducidos con aproximación suficiente.

Casi un siglo después, en 1574, cuando ya se conocía en buena medida la geografía de América y estaba casi trazado por completo el perfil real de sus costas en cartas y mapas -en los que las posiciones de los lugares geográficos se consideraban exactos-, Juan López de Velasco, cosmógrafo y cronista mayor de Indias escribió la Geografía y descripción universal de las Indias (25), no publicada por considerar quienes la censuraron que desvelaba secretos que atentaban contra los intereses de España, referentes a las longitudes geográficas. Y precisamente una de esas longitudes era la del meridiano de Tordesillas.

López de Velasco escribió que la línea divisoria venía a caer entre los $29^{\circ}$ y $30^{\circ}$ al oeste de las Canarias y como los grados de Velasco eran de 70 millas por grado, reduciéndolos a los de 66 $2 / 3$ que utilizó Ferrer en sus cálculos, la longitud del meridiano quedaba comprendida entre los $30^{\circ}, 5$ y $31^{\circ}, 5$ respecto de las Canarias (26). Ahora bien como la diferencia de longitud entre estas islas y las de Cabo Verde es de $9^{\circ}$ sexagesimales, ó $10^{\circ}$ de 66 2/3 millas romanas, la posición del meridiano aceptada por Velasco, traducida al módulo de Ferrer, estaba comprendida entre los $20^{\circ}, 5$ y $21^{\circ}, 5$, o sea dos grados y medio o un grado y medio más a levante que la calculada por éste; una diferencia mínima si se tiene en cuenta el progreso experimentado por la

(25) Esta Geografía se publicó por primera vez en 1880 en el Boletín de la Real Sociedad Geográfica, de Madrid.

(26) López DE VELASCo, [25], págs. 3-5. 


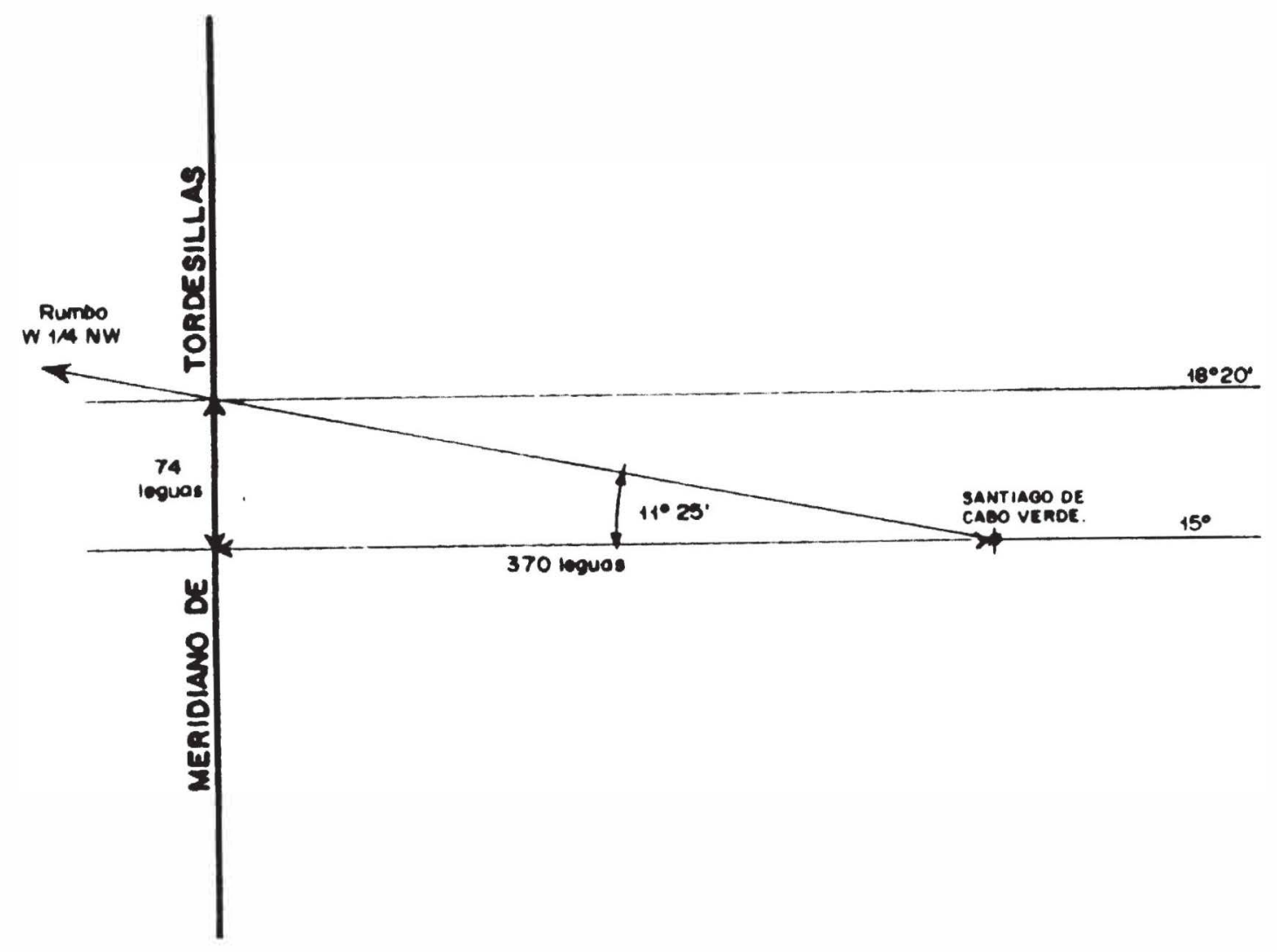

FIG. 3. Cálculo náutico de la posición del meridiano de Tordesillas tomando como origen la Isla de Santiago de Cabo Verde, según Jaime Ferrer de Blanes. (1495).

cartografía y la náutica en el curso del siglo XVI. Precisa Velasco que el meridiano cortaba la costa de Brasil por el cabo Humos en el norte y la isla del Buen Abrigo en el sur. Este cabo Humos es la punta Humos que ya en 1551 López de Gómara situó a $1^{\circ}, 5$ al sur de la línea equinoccial (27) y es el mismo cabo que Alonso de Chaves denominó punta de Eumus situada 1 2/3 grados debajo de dicha línea (28), seguramente la actual isla de São João. En todo caso la posición dada por Velasco, Gómara y Chaves es sensiblemente coincidente con la que calculó Ferrer de Blanes más de medio siglo antes. tín".

(27) Historia general de las Indias, epigrafe dedicado al "Cabo de San Agus-

(28) Alonso de Chaves, Quatripartitu en Cosmographia práctica, Capítulo XXI, "De los puertos, ríos y cabos de la costa de Marañón", (Sevilla 1537) Madrid, Museo Naval, 1983. 


\section{El TRAZADO DEL MERIDIANO DE TORDESILLAS EN LOS MAPAS Y CARTAS DE MAREAR}

Jaime Ferrer resolvió teórica y prácticamente el problema posicional de la línea de demarcación, pero las cuestiones de fondo, políticas y técnicas, subsistían y las comisiones encargadas de estudiarlo conjuntamente no llegaron a reunirse. Tampoco había motivos apremiantes de litigio entre España y Portugal que exigieran una pronta delimitación de las respectivas demarcaciones, de ahí que en la primera carta - de las hoy conocidasen que aparece una línea de demarcación, la de 1500 de Juan de la Cosa, represente éste el meridiano que propuso Colón al término de su primer viaje - fijado en la bula pontificia Inter Coetera II- que ya no tenía vigencia en ese año, puesto que privaba el meridiano acordado en Tordesillas. Si entre 1494, año en que se firmó este Tratado y 1500 hubiera surgido algún contencioso competencial imperativo entre los dos países, es de suponer que Juan de la Cosa habría trazado en su carta la línea de Tordesillas.

La necesidad real de materializar en las cartas de marear el meridiano de Tordesillas se puso en evidencia cuando en la corte de Lisboa se recibió la nueva de que el 27 de abril de 1500 Pedro Alvares Cabral, en viaje a la India al mando de una flota, descubrió tierra a poniente del Atlántico en los $16^{\circ}$ sur, que bautizó, como Tierra de Santa Cruz. Como es natural, la noticia interesó vivamente al rey Manuel, quien deseoso de saber si aquella tierra caía dentro o fuera de su demarcación, en mayo de 1501 despachó una expedición exploratoria al mando de Gonzalo Coelho, con Américo Vespucio como cosmógrafo, para investigar la posición de la tierra de Santa Cruz, tenida por isla por Cabral y sus pilotos.

En esa misma región de la actual costa de Brasil tres meses antes, el 20 de enero del mismo año, Vicente Yáñez Pinzón descubrió una extensa porción del litoral, situada unos $6^{\circ}$ más al norte de la que luego arribó Cabral, e incluso sus pilotos reconocieron la desembocadura del Amazonas en la época del equinoccio de primavera, fijando su posición por latitud observada. Los descubrimientos sucesivos de Pinzón y Cabral, distantes tres meses en el tiempo y $6^{\circ}$ de latitud en el espacio, han sido motivo de desacuerdo sobre la primacía en el descubrimiento de Brasil. Historiadores portugueses y brasileños se la otorgan a Cabral y los historiadores españoles, que no copian a éstos, sostienen que 
Pinzón fue el verdadero descubridor de aquel país. Como aquéllos parten del supuesto de que la colonia de Brasil se creó a partir del enclave hallado por Cabral y los españoles se apoyan en el hecho de que la costa descubierta por Pinzón forma parte de la misma nación, puede decirse que a todos y a ninguno les acompaña la razón; razón por la que la discrepancia de opiniones subsiste todavía. Tras esta digresión volvamos a nuestro tema.

En una de las célebres cartas que Vespucio escribió a Lorenzo de Médicis, la de 1502, dándole noticia de este viaje decía que desde las islas de Cabo Verde las naves lusitanas siguieron rumbos comprendidos entre leveche y mediodía (SW y S) y después de 64 días de navegación recorrieron 800 leguas de costa, navegando a la cuarta de leveche hacia poniente, es decir al SW 1/4 W, indicando con este dato la dirección - aproximada- del litoral brasileño. En esta epístola Vespucio no alude a cálculos de posición realizados en el curso del viaje, si bien en otra posterior -la denominada "fragmentaria» - fechada el mismo año precisa que navegaron a la vista de la costa hasta alcanzar los $32^{\circ}$ de latitud sur a una distancia de 1.600 leguas de Lisboa y una longitud de 5 $1 / 3$ horas respecto de esta capital, o cerca de 8 horas en relación con el meridiano de Ferrara. Ambos cálculos son erróneos, puesto que situaba la posición alcanzada en el océano Pacífico y de ellos no puede deducirse que Vespucio calculara el lugar de la costa por la que pasaba la línea de partición.

Sin embargo, con la información náutica obtenida en este viaje se confeccionaron varias cartas mapamundis, como son las anónimas de King Hamy y Cantino, ambas construídas en fecha próxima a 1502. En esta última el autor representó el meridiano de Tordesillas trazándolo 370 leguas al oeste de la isla de San Antón de Cabo Verde, la más occidental del grupo, con la intención política de favorecer los intereses de la corona portuguesa. Esta tendencia a incluir la mayor extensión posible de territorios al oeste del meridiano de Tordesillas -errores de cálculo y de trazado aparte- se pone de manifiesto con la orientación geográfica del perfil de la costa de Brasil, forzadamente inclinada en dirección sudeste, contraria a la real, para dejar a levante del meridiano una mayor extensión de territorio.

También las cartas de Caverio de c.1505 y de Pedro Reinel de c.1519 - ésta menos acusadamente- señalan la tendencia general de dibujar la costa brasileña en esa dirección. En cambio otras cartas mapamundi de la misma época que la de Cantino presentan el trazado de esa costa más acorde con la orientación verda- 
dera, a pesar de los errores que se pueden imputar a las deficiencias técnicas y a los procedimientos de trazado cartográfico en uso; son las cartas de influencia vespuciana. Entre ellas, la de King-Hamy, singular por cuanto el autor trazó dos líneas ecuatoriales; una en posición tangenteando la costa norte del golfo de Guinea, donde estaba situado el fuerte y factoría portuguesa de San Jorge de Mina; otra delineada en su verdadera posición, manifestando con ello su duda del autor del lugar de trazado exacto de la línea equinoccial. El doble trazado de esta línea prueba la anterioridad de esta carta respecto de la de Cantino, en la que figura ya trazada esta línea en posición correcta.

Otra carta temprana, posterior a la de Cantino, que también representa el meridiano de partición, es la anónima denominada Oliveriana de Pesaro, atribuida a Vesconte de Magiollo (c.1505), inspirada en parte en la información portuguesa del viaje de Coelho, como lo indica el perfil de corte vespuciano de la costa de Brasil y en buena medida copiada de la que confeccionó Juan de la Cosa en 1500, según puede verse en la copia de Magiollo la forma singular que Cosa dio a la isla de Cuba y la dirección este oeste de la costa situada al norte de las Grandes Antillas, tal y como su descubridor, Juan Caboto, la dio a conocer.

A pesar de la materialización en las cartas de marear de la línea de demarcación esta solución no proporcionó a los navegantes lusitanos y españoles una indicación práctica que les ayudara a saber fácilmente cuándo vulneraban el Tratado de Tordesillas, mediante el cálculo de la posición de las naves, dada la imposibilidad de hallar la longitud en la mar con aceptable aproximación. Para obviar esta dificultad, la regla práctica seguida por unos y otros era la de tomar como referencia la posición del cabo de San Agustín situado en los $8^{\circ}$ de latitud sur. Consideraban que las tierras ubicadas al norte de esa latitud pertenecían a los Reyes de España y las del sur al de Portugal.

Esta práctica tuvo algunas veces sus fallos. Cuando en 1515 los españoles capturaron una carabela portuguesa al norte de este cabo, por cuya causa hubo una reclamación diplomática por parte del rey Manuel I y una orden terminante del Rey Fernando para que se determinara en la Casa de la Contratación, con exactitud, la latitud del cabo de San Agustín, pues el capitán de la carabela apresada alegaba en su defensa que la captura se efectuó cuando navegaba al sur de ese paralelo. El meridiano de demarcación, que modernamente ha sido motivo de múltiples especulaciones en cuanto a su posición, no fue el jalón práctico 
por el que se guiaban los navegantes ibéricos, sino el más fácil cotejo de la latitud en relación con dicho cabo.

\section{El MERIDIANO DE TORDESILLAS ADQUIERE NUEVO SIGNIFICADO DESPUES DEL DESCUBRIMIENTO DE LAS ISLAS MOLUCAS. INTENTO DE DETERMINACIÓN DE LA POSICIÓN DEL ANTIMERIDIANO}

Después de los viajes de reconocimiento de 1501-1502 y 15031504 realizados por Coelho y Américo Vespucio a la costa meridional de Brasil, en Portugal se organizaron dos expediciones por cuenta de particulares con fines de explotación de la tierra de Santa Cruz, descubierta por Cabral. Pero no profundizaron en dirección al extremo sur de la costa, cuyo perfil geográfico quedó sin determinar, desconociéndose en consecuencia a qué demarcación pertenecía. La corona portuguesa se desentendió de Brasil y dio prioridad al comercio de sus flotas en la región índica, en tenaz lucha con los árabes por controlar el tráfico en los mares del sur y sudeste de Asia, lo que al fin se consiguió con la conquista de los enclaves de Goa (1510) y Malaca (1511): éste el puerto más pujante de Asia al que llegaban valiosos productos de intercambio del extremo oriente y de las productivas islas de las especias tan ambicionadas en Europa, es decir de las Molucas o Maluco.

El conocimiento de estas noticias en la corte española y la creencia de los cosmógrafos de que las islas especieras quedaban dentro de su propia demarcación, según lo acordado en Tordesillas conforme con la teoría de Ptolomeo sobre la extensión del Viejo Mundo, determinaron al Rey Fernando a disponer una expedición marítima por el cabo de Buena Esperanza para hacer valer sus derechos de posesión de las islas Molucas. El piloto mayor de la Casa de la Contratación, Juan Díaz de Solís, fue el designado para dirigirla.

En la capitulación concedida a Solís el 27 de marzo de 1512 se establecía:

Item, porque a mi es fecha relacion por personas muy sabias en el arte de navegar que la demarcación se debe hacer a la línea equinocial en medio de la isla de Celan, e por longitud de nuestro meridiano ciento veinte grados a la parte oriental debeis mucho mirar en ello, para que en Dios y en vuestra ciencia hagais la demarcación los mas justamente que pudieredes de manera que ninguna de las partes reciba agravio y dejareis las 
mejores señales que pudieredes para que la dicha demarcación sea de aqui adelante sabida y clara, perpetuamente, entre estos Reinos y la Corona de Portugal (29).

El cosmógrafo «Martin Dãopias e diz q'he bőo estrologo e nåo esta agora aqui que diz q'he ido a Ingratera e q'esperão cada dia por ele» (30), era quien debería realizar los cálculos para situar geográficamente la posición del meridiano opuesto al de Tordesillas (el antimeridiano), limite oriental de las demarcaciones, con objeto de legitimar la pertenencia de esas islas. Esta expedición fue suspendida ante las peticiones del rey de Portugal Manuel el Afortunado y por haber tenido noticia el monarca castellano de que los navegantes portugueses habían llegado ya a las Molucas, con lo quedaba excluida su competencia en virtud del derecho adquirido por éstos como primeros ocupantes de tierras no pertenecientes a reyes cristianos.

\section{LA POSICIÓN DEL MERIDIANO Y EL ANTIMERIDIANO DE TORDESILLAS EN EL VIAJE DE MAGALlANES-ElCANO}

Tras el descubrimiento del Mar del Sur por Vasco Núñez de Balboa (1513) el Rey Fernando comisionó al mismo Juan Díaz de Solís (1515) para dirigir una expedición que debería acceder al nuevo mar, buscando un paso por el sur de la costa de Brasil. Después debería llegar al litoral de Castilla del Oro (Panamá), enviar desde allí noticias a la corte y explorar la costa hasta navegar 1.700 leguas con el fin de alcanzar los aledaños de las Molucas. La trágica muerte de Solís en el Río de la Plata frustró los fines de la expedición y el viejo monarca español murió sin ver colmada su esperanza.

La dicha de alcanzar las Molucas le cupo a su nieto, Carlos I, al confiar el mando de una nueva expedición al capitán y navegante portugués - luego naturalizado castellano- Fernando de Magallanes quien, junto con el cosmógrafo Rui Falero, ofrecieron

(29) José Toribio Medina, Juan Diaz de Solis, Santiago de Chile 1897, tomo II, págs, 64-66. Este es el primer documento oficial en el que se alude al cálculo de la posición del antimeridiano de Tordesillas, poniendo sobre el tapete de la política internacional la necesidad de determinar el verdadero trazado del meridiano de Tordesillas.

(30) Carta del ministro portugués Juan Mendez de Vasconcelos al rey de Portugal, fechada el 7 septiembre de 1512. Transcrita por FERNÁNDEZ DE NAVARRETE, [1], tomo III, doc. XXXIV. 
sus servicios al Rey de España, para navegar por el Mar del Sur hasta las Molucas a través del paso marítimo que suponían que existía al sur de la costa de Brasil, Magallanes y Falero afirmaban que las islas de las especias estaban dentro de la demarcación castellana y trajeron consigo a España mapas y cartas de marear para explicar y justificar la licitud y viabilidad de su proyecto.

Sebastián Âlvarez - agente del rey de Portugal en Sevillacomunicó a Manuel I que Magallanes le mostró una «poma y carta que hizo el hijo de Reineb (31), de trazado distinto de las cartas planas; debía ser una proyección polar (32) similar a la que trazó Pedro Reinel en 1522. Bartolomé de las Casas confirma la noticia de Álvarez y escribe que Magallanes trajo un

globo bien pintado, en que toda la tierra estaba y alli señaló el camino que había de llevar salvo que el estrecho dejó de industria en blanco, porque alguno no se lo saltease (33).

\section{Y Bartolomé Argensola dice a su vez que Magallanes}

pasó a Castilla trayendo un "planisferio» dibuxado por Pedro Reinel. Por el cual, y por conferencias, que por carta auia tenido con Serrano, persuadió al Emperador Carlos V que las Molucas eran de su derecho (34).

No se refiere Argensola a una poma y carta, como Álvarez, ni a un globo, como Las Casas, sino a un planisferio, pero ésto no contradice, más bien refuerza, lo que registran otros cronistas dado que Magallanes y Falero pudieron manejar cartas de diversos tipos, fueran cartas de proyección polar, de forma global o las cartas planas.

Una de las cartas de la época en que se preparaba la expedición en Sevilla es de particular interés: la de c. 1519, de Jorge Reinel, cartógrafo que acompañó Magallanes en su venida a España. Presenta la costa meridional brasileña hasta la latitud de cabo Frío prolongada en dirección meridional, apuntando en la que Magallanes pensaba buscar el estrecho, y las islas Molucas en la parte occidental del mar del Sur, junto a la línea equinoccial,

(31) Fernández de NavarRete, [1] tomo IV, doc. XV, pág. 143; el subrayado es nuestro.

(32) Marcel Destombes, "The Chart of Magellan" Imago Mundi n XII.

(33) LAS CASAS, Historia de las Indias, lib. III, cap C.

(34) Bartolomé Leonardo de Argensola, La conquista de las islas Molucas, Madrid 1609, pág. 16. 
detalle que contemplado en la fecha de su elaboración y a la vista del número de leyendas que en ella hay escritas, la hacen acreedora al supuesto de ser una de las que Magallanes mostró a Carlos I.

En cualquier caso las cartas que Magallanes y Faleiro utilizaron para apoyar su proyecto debieron tener trazado el meridiano de Tordesillas, como la de Reinel, y ambos creían saber la posición exacta de la línea de demarcación oriental con información obtenida en fuentes oficiales de Lisboa $y$, en particular, por las noticias que comunicó a Magallanes su amigo Francisco Serrăo, piloto y codescubridor de las Molucas con Antonio Abreu, en 1511. La longitud geográfica de las líneas occidental y oriental de demarcación así como las posiciones de los puntos determinantes en las que fundamentó el proyecto de viaje quedaron expresas en el Memorial que el capitán portugués dejó a Carlos I antes de darse a la vela en Sevilla, el 10 de octubre de 1519.

Tomando como origen la isla de San Antón, de Cabo Verde, Magallanes situaba la línea de demarcación en los $17^{\circ}$ de latitud y $22^{\circ}$ al oeste de la isla de San Antón. Como esta isla está $25^{\circ}$ al W de Greenwich, la longitud del meridiano de Tordesillas quedaba situada en los $47^{\circ}$. Seguidamente, con referencia a los cabos de San Agustín, Santa María y Buena Esperanza, situado $65^{\circ}$ al este de la línea de Tordesillas, o sea $18^{\circ}$ al este de Greenwich, posicionó, el puerto de Malaca en la derrota ENE a 1600 leguas del cabo de Buena Esperanza; este puerto del sudeste asiático distaba de la otra línea de de la demarcación -el antimeridiano$17^{\circ}, 5$ grados. De las cinco islas que constituye el grupo del Maluco, las tres más cercanas al antimeridiano están alineadas de norte a sur a $2^{\circ}, 5$ de longitud y la isla de enmedio debajo de la equinoccial; las otras dos, dispuestas también de norte a sur, estaban $4^{\circ}$ el este del antimeridiano y $2^{\circ}$ al sur de la equinoccial.

De la argumentación geográfica contenida en estos párrafos se deduce que Magallanes desconocía la longitud verdadera de las Molucas dado que fijó la posición del antimeridiano a partir de un lugar, Malaca, situado por rumbo y distancia desde el cabo de Buena Esperanza, por lo tanto afectado de errores que implicaba la falta de exactitud de las distancias estimadas a ojo en la mar. También se alejan de las longitudes reales las posiciones de los demás puntos geográficos citados en el Memorial - salvo la de la isla de San Antón y la latitud del cabo de San Agustín-, de modo que la suma de todos los errores se traducía en una posición del antimeridiano desplazada $9^{\circ}$ más al oeste de 
la real. Con lo cual las islas Molucas quedaban entre $2^{\circ}, 5$ y $4^{\circ}$ dentro del hemisferio español, cuando en realidad están entre $6^{\circ}$ y $8^{\circ}$ al oeste.

Con cifras diferentes, los cálculos náuticos realizados por los pilotos durante el viaje de circunnavegación del mundo confirmaban sin embargo la teoría de Magallanes. El piloto Francisco Albo anotó en su Diario de navegación la posición del cabo de las Vírgenes: $52^{\circ}$ de latitud y $52^{\circ} 30^{\prime}$ de longitud (35). En este Diario no figura longitud alguna hasta que las naves fondearon en la isla de Suluan (16 de marzo de 1521), del archipiélago de San Lázaro o de las Filipinas. Albo situó Suluan en $9^{\circ}$ y dos tercios de latitud y $189^{\circ}$ de longitud respecto de la línea meridiana (36) y añade que esa isla y la de Yunagan (Samar) están a $106^{\circ} 30^{\prime}$ de longitud de cabo Fermoso. La línea meridiana para Albo, contramaestre de la nao capitana Trinidad, que mandaba Magallanes, parece que debería ser el meridiano de Tordesillas que éste tomaba como referencia. Sin embargo, para él el origen de las longitudes era la isla de Hierro.

En su relato del viaje, Pigafetta daba también las longitudes de algunos lugares y, salvando las imprecisiones en los cálculos propias de los métodos náuticos utilizados en la época, las diferencias constantes entre las longitudes anotadas por éste y las de Albo - calculadas por distintos pilotos y referidas a distintos meridianos de origen - convalidan su aceptabilidad: aunque no su exactitud, explicando además, el que Magallanes, después de alcanzar Samar, siguiera navegando al oeste, convencido de encontrarse dentro de la demarcación española. Lo mismo hicieron quienes le sucedieron en el mando de la expedición cuando fue asesinado en Mactán. Continuaron progresando hacia el oeste hasta alcanzar la máxima longitud de $176^{\circ} 40^{\prime}$ a partir de la línea de Tordesillas, hasta Burney. A partir de este lugar decidieron navegar al este para alejarse de la demarcación portuguesa y seguir luego en dirección sur en demanda de las Molucas. Según los cálculos de los pilotos retrocedieron cuando estaban a $3^{\circ} 20^{\prime}$ al este del antimeridiano, el cual situaron en sus cartas de marear y por lo tanto para ellos las Molucas estaban dentro de la demarcación española.

Es posible que este falso resultado no se hubiera dado si el

(35) Albo estuvo embarcado en la nao capitana, Trinidad, hasta que después de la muerte de Magallanes los reajustes de personal aconsejaron designarlo piloto de la Victoria.

(36) Diario, dia 16 de marzo de 1521. 


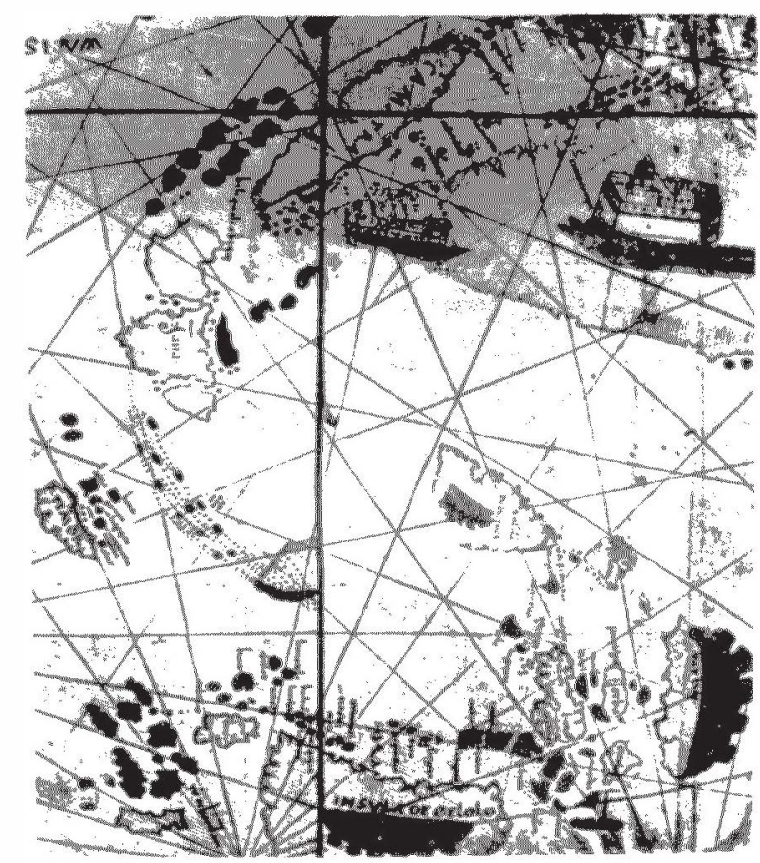

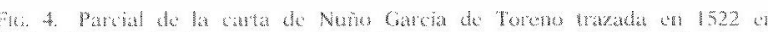

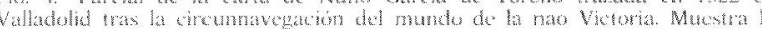

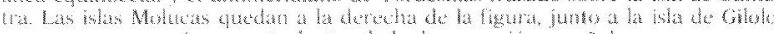

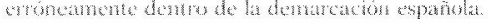


cosmógrafo mayor de la expedición, Andrés de San Martín -que sustituyó a Rui Falero-, no hubiera sido asesinado en la celada tendida por los indígenas de Cebú el 1 de mayo de 1521. Sus acertados cálculos astronómicos realizados en el viaje permitieron conocer las posiciones casi exactas - por longitud y latitud- de algunos puntos de la costa sudamericana, entre ellos la bahía de San Julián, los de los cabos de acceso y salida del estrecho de Magallanes, calculadas con los eclipses, conjunciones y oposiciones de Luna y de los planetas observados en tierra.

Creemos, por lo tanto, que no son ciertas las imputaciones de manipulación de los datos náuticos del viaje de Magallanes-Elcano para que las Molucas quedaran dentro de la demarcación española, sino más bien producto de los errores en el cálculo de las longitudes por medio de la estima. Saliendo al paso a estas acusaciones, el factor portugués de las Molucas en aquella época, Duarte Resendi, en cuyo poder quedaron el Diario y los papeles de San Martín, incautados en la nao Trinidad, opinaba sobre esta cuestión que uforzoso era no passar por escritos especulativos que no siendo comprobados por experiencias por lo menos eran dudosos" (37).

Tan dudosas eran las especulaciones sobre la posición de las Molucas y del antimeridiano en las Juntas de Badajoz-Elvas que los delegados portugueses no hicieron uso de los documentos incautados en la Trinidad para demostrar la posible falsedad de los datos náuticos contenidos en ellos. Tampoco aportaron cálculos ni mapas fiables que demostraran que las Molucas pertenecían a su rey.

\section{EL MERIDIANO Y EL ANTIMERIDIANO DE TORDESILLAS EN LAS CARTAS DE GARCía DE TORENO Y ANÓNIMA DE PEDRO REINEL}

Como es natural el viaje de circunnavegación a la Tierra tras la llegada a las Molucas a través del Mar del Sur, bautizado "Pacífico» por Magallanes, tuvo notable incidencia en la cartografía. No tanta como hubiera sido deseable debido a las muertes del director de la empresa, Magallanes, y del cosmógrafo mayor de la expedición, Andrés de San Martín, y la desaparición de gran parte de los registros y diarios del viaje, causa de la pérdida de importantes datos y noticias inéditas.

(37) Argensola, [33], pág. 45. 
A pesar de estas limitaciones, con la información geográfica y náutica traída a España al regreso de la nao Victoria -el 6 de septiembre de 1522 - el cartógrafo de la Casa de la Contratación, Nuño García de Toreno, construyó una carta comprensiva del sur y sudeste asiático e islas Molucas. En ella no figura el estrecho de Magallanes, razón por la que se la consideró antaño como parte de otra carta de mayor amplitud geográfica, si bien una observación de los límites de encuadre ofrece pruebas válidas para pensar que es una carta completa. La premura con que fue elaborada en 1522 en la misma corte (Valladolid), a petición de Carlos I, indica que el motivo principal de su trazado residía en el interés del monarca por conocer la posición de las Molucas en relación con el antimeridiano de Tordesillas. El trazado de esta línea sobre la península de Malaca, más al oeste del lugar calculado por Magallanes, explica la determinación errónea de las longitudes halladas por los pilotos a partir de los rumbos y distancias navegadas; es decir, por estima, en vez de hacerlo mediante la observación astronómica como era la práctica utilizada por Andrés de San Martín.

Otra carta construida en base a la información acopiada en el viaje es la anónima de 1522, atribuida a Pedro Reinel. Es de proyección polar centrada en el polo sur y comprende las regiones meridionales de Africa y América, mostrando un trazado de la costa de Brasil corregido respecto de las cartas portuguesas anteriores. No figura en ella el estrecho del Espíritu Santo, nombre que dio Magallanes al paso que él mismo descubrió, pero aparecen dibujadas unas islas junto al extremo sudoriental del continente americano, en la posición de las Malvinas, que indican que los datos utilizados para su trazado no pudieron ser facilitados más que por los pilotos de la nao San Antonio, que regresó a Sevilla en mayo de 1521, antes que la Victoria, sin pasar el estrecho.

Esta carta de Reinel tiene la particularidad de presentar como origen de longitudes el meridiano de Tordesillas trazado sobre la desembocadura del Amazonas. El antimeridiano pasa por el este de las Molucas y cercano a ellas, como suponía Magallanes. Elaborada en Sevilla (38), su trazado corresponde al de la forma de poma y carta citada por Sebastián Álvarez en 1519. Contiene,

(38) Los Reinel permanecieron en Sevilla hasta la primavera de 1524, por lo menos. El 27 de mayo sendas reales cédulas asignan a Pedro 35.000 maravedís y a Jorge 30.000 de salario cada año. Archivo General de Indias, Indiferente General, leg. 1.204. Publicadas literalmente por José Toribio MedinA en El veneciano Sebastián Caboto, Santiago, nota 58, pág. 356. 
por lo tanto, información de origen portugués, anterior al inicio del viaje, y datos obtenidos durante la navegación de la San Antonio hasta la llegada a la embocadura oriental del estrecho de Magallanes y su regreso a Sevilla.

\section{NOTA FINAL: LA LIQUIDACIÓN DEL CONTENCIOSO HISPANO- PORTUGUÉS SOBRE LA POSESIÓN DE LAS MOLUCAS}

Como fundamento de sus argumentos los representantes españoles en las negociaciones de Badajoz-Elvas sostenían que la longitud del cabo de San Agustín estaba en los 18 ó 19 grados al oeste de las Canarias y el meridiano de Tordesillas 170 ó 180 leguas tierra adentro, pasando sobre el cabo de Humos y la isla del Buen Abrigo. Por su parte los portugueses alegaban que la longitud de dicho cabo estaba entre los 12 y 13 grados de longitud respecto de dichas islas, es decir $6^{\circ}$ más al este, y que la línea de demarcación se situaba 175 leguas al oeste de ese cabo, de modo que dentro de ella quedaba inclusas la desembocadura del Río de la Plata (39), la posterior ciudad de Asunción y las islas de los Bacalaos, o sea Terranova (40). Si en esta cuestión la razón quedaba del lado de los españoles, no sucedía lo mismo en su afirmación de que las Molucas estaban $30^{\circ}$ dentro de su demarcación, pues realmente estaban dentro de la portuguesa.

Aparte de que cada grupo de delegados alegara razones verdaderas, unas, y no tanto otras, en defensa de sus intereses, el origen del desacuerdo estaba en la dificultad práctica de la determinación in situ de los lugares de la geografía por donde pasaban el meridiano y antimeridiano de Tordesillas. Todos sabían que uno y otro eran opuestos $180^{\circ}$ en la línea equinoccial, y si existían lugares donde la longitud era conocida con aproximación, en otros - como el Río de la Plata, las islas de los Bacalaos y la Molucas, por ejemplo- donde no se había calculado por los procedimientos astronómicos en uso, se ignoraba la longitud verdadera. En consecuencia a ninguna de las partes satisfacía la solución aportada por sus antagonistas y las razones de unos eran sistemáticamente rechazadas por los otros.

(39) LóPEz de Velasco, [25], pág. 4.

(40) El lector curioso puede realizar los cálculos de las longitudes manejadas por los litigantes considerando el grado de 70 millas, o 17,5 leguas, utilizado por unos y otros, convirtiéndolo en grado sexagesimal y comparando aquellas longitudes con las calculadas. 
La solución del litigio de las Molucas se logró con el Tratado de Zaragoza en 1529, mediante el cual Carlos I cedía estas islas al monarca portugués, con derecho a retrovendo, a cambio de 350.000 ducados de oro. Y ante las dudas de la posición real de las islas, para dar carácter legal al convenio se recurrió al artificio de trasladar el antimeridiano $17^{\circ}-296,5$ leguas (41) - al este de las Molucas, medidos sobre la línea equinoccial, de modo que las islas quedaran dentro de la demarcación lusitana. Esta decisión explica por sí misma que nadie estaba entonces en condiciones de afirmar cual era la verdadera longitud geográfica de las islas especieras. De lo contrario no se habría cometido la "tropelía" geográfica de inventar un antimeridiano que no estaba situado $180^{\circ}$ en oposición respecto del de Tordesillas.

En varias ocasiones las Cortes castellanas solicitaron a Carlos I que hiciera valer su derecho de recuperar la posesión de las Molucas mediante la restitución al rey de Portugal los 350.000 ducados que desembolsó en su adquisición. En el año 1548 los procuradores a Cortes reunidos en Valladolid pidieron por escrito que concediera una prórroga de seis años más el arriendo de las islas a Juan III y las recuperara la Corona española, a pesar de que de momento se desequilibrara la balanza hacendística, pero el emperador contestó negativamente desde Flandes, donde a la sazón se encontraba (42). Las pérdidas sufridas por las flotas destacadas hasta entonces a las islas de las especias para tomar posesión, sin encontrar una derrota de retorno a través del Pacífico, para evitar el largo periplo de la circunnavegación de la Tierra, y la permanente necesidad numerario para apoyar la política europeista del emperador - en detrimento de los intereses hispánicos- influyeron negativamente en su ánimo para acceder a la petición de sus cortesanos.

En 1586, cuando Felipe II era Rey de España y de Portugal, encargó al matemático y cosmógrafo Jaime Juan (43), la determinación de las longitudes de sus dominios en Filipinas mediante el cálculo astronómico, pero Juan falleció recién llegado a aquellas islas y el problema quedó sin resolver. Por último el desbordamiento de la línea de demarcación por parte de los colonos brasileños por el Mato Grosso, dejaron sin efectos de hecho el

(41) López de Velasco, [25], pág. 5.

(42) Francisco LÓPEZ DE GÓMARA, Historia general de las Indias, epígrafe "Empeño de la Especiería".

(43) Ernesto SCHÄFER, "El cosmógrafo Jaime Juan" Investigación y progreșo, Madrid 1936. 
Tratado de Tordesillas en Brasil, aunque continuó el contencioso entre España y Portugal en torno a la colonia de Sacramento. Las discusiones subsecuentes se zanjaron en primera instancia con el Tratado de Límites de 1750 -que no fue ratificado- y formalizado en el Tratado de San Ildefonso de 1777. Se daba fin así a una disputa político-geográfica que se prolongó justamente trescientos años, desde el Tratado de Alcaçovas-Toledo de 1479. 